\title{
A fala egocêntrica da criança de seis anos na construção coletiva da escrita
}

\author{
Six year old's egocentric speech in the collective \\ construction the writing
}

\section{Le discours égocentrique de l'enfant de six ans dans la construction collective de l'écrit}

\author{
Maria Fernanda Farah CAVATON
}

Silviane BARBATO

\begin{abstract}
RESUMO
Neste artigo apresentamos e analisamos os dados sobre os usos e as funções da fala egocêntrica de quatro crianças de seis anos nas suas produções gráficas livres: o desenho e as escritas iniciais. Nosso estudo foi desenvolvido na perspectiva da psicologia sociocultural na qual $o$ desenvolvimento é construído dialogicamente durante atividades de ensinar e aprender em processos de letramento multimodal. Além disso, as interações e as resoluções de problemas em sala de aula envolveram práticas sọciais baseadas nos modos de comunicação - oral, visual e gráfico. Analisamos quatro sessões gravadas em áudio e vídeo de sessenta minutos num primeiro ano do ensino fundamental. Das quatro sessões proporcionadas pela professora da classe, três foram de reconto_de história infantil e uma de escrita livre. Utilizamos o episódio como unidade de análise. Âplieames três categorias da literatura para analisar as falas egocêntricas e criamos uma quarta categoria para a situação específica encontrada em nossa pesquisa. Os resultados indicaram o uso da fala egocêntrica com a função organizadora do desenho e de soletração da escrita livre e o uso das falas egocêntricas com as seguintes funções geradoras de construção de conhecimento na intersubjetividade: a) comentário de outro social; b) comentário do próprio falante dirigido a outros sociais; c) falas egocêntricas em outros sociais; d) comentário de avaliação; e) falas egocêntricas de soletração "coletivizada"; f) comentário de concordância ou discordância.
\end{abstract}

Palavras-chave: fala egocêntrica, pedagogia dialógica, escrita infantil, desenho infantil, letramento multimodal. 


\begin{abstract}
In this article we aimed at analyzing data on the uses and functions of four six-years-olds 's private speech prompted during free graphic productions activities such as drawing and initial writing. Our study was developed from a cultural psychology perspective in which knowledge is constructed dialogically during teaching-learning activities in multimodal literacy processes. In addition, classroom interactions and problem solving involve social practices based on oral, visual and graphic modes of communication. We analyzed four 60 minutes sessions filmed in a first year classroom Junior school in which three sessions involved recount activities and one free writing session all conducted by the classroom teacher. Having episodes as unit of analysis, we applied the categories developed by literature to analyze private speech and created another category from the indexes of the specific situations. Results indicated that the use of egocentric speech functioned in order to organize drawing and spelling during free writing activities. In addition, the use of egocentric speech acquired the following functions directed to generate knowledge in intersubjectivity: a) as a commentary of the social other; b) a commentary of the speaker himself directed to the social other; c) an egocentric speech of the social other; d) an assessment commentary; e) private speeches in collective spelling; f) as present participants commentaries of agreement or disagreement.
\end{abstract}

Index terms: dialogical pedagogy, egocentric speech, children's writing, children's drawing, multimodal literacy.

\title{
RÉSUMÉ
}

Dans cet article nous présentons et analysons les données sur les emplois et les fonctions du discours égocentrique de quatre enfants de six ans dans leurs productions graphiques libres: le dessin et les premiers écrits. Notre étude a été développée sur la perspective de la psychologie socioculturelle dans laquelle le développement est construit de façon dialogique au cours d'activités d'enseignement et d'apprentissage de processus d'alphabétisation multimodale. De plus, les intéractions et les résolutions de problèmes en salle de classe ont fait appel aux pratiques sociales basées sur les moyens de communication - oral, visuel et graphique. Nous avons analysé quatre séances enregistrées en audio et vidéos de 60 minutes dans une classe de CP. Parmi les quatres séances que l'institutrice nous a offert, trois séances avaient pour objectif de redire des histoires et la dernière séance avait pour objectif l'écriture libre. Nous avons utilisé l'épisode comme unité d'analyse. Nous avons appliqué trois catégories de la littérature pour analyser les discours égocentriques et nous avons créé une quatrième 
catégorie pour la situation spécifique rencontrée lors de notre recherche. Les résultats ont indiqué l'emploi du discours égocentrique avec la fonction d'organisation du dessin et d'épeler l'écriture libre et aussi l'emploi des discours égocentriques avec les fonctions génératrices de construction de connaissance dans l'intersubjectivité: a) commentaire d'autrui ; b) commentaire de celui qui parle vers les autres; c) discours égocentriques vers les autres; d) commentaire d'évaluation; e) discours égocentriques d'épellation collective; f) commentaire d'accord et de désaccord.

Mots-clés: discours égocentrique, pédagogie dialogique, écriture des enfant, dessins des enfants, alphabétisation multimodale.

\section{I - Introdução}

O foco principal deste artigo consiste em analisar os usos e funções da fala egocêntrica no desenvolvimento cultural de crianças de seis anos, quando de seu ingresso no primeiro ano do ensino fundamental, com a função mediadora para a construção da sistematização da escrita. A-faixa etária de seis anos foi escolhida por ser o momento em que a criança está construindo a linguagem escrita, tendo a mediação da fala egocêntrica e do desenho, enquanto modos de comunicativos no contexto escolar da educação infantil e do primeiro ano do ensino fundamental.

Esse tema foi desenvolvido como parte de uma pesquisa guardachuva $^{1}$ com crianças de seis anos em sala de aula do $1^{\circ}$ ano do ensino fundamentat numa escola públiea de Distrito Federal, denominado de Bloco Inicial de Alfabetização (BIA 1), na qual estudamos as mediações da fala, do desenho e da escrita inicial na construção de conhecimento nas interações criança/criança e criança/professora. As atividades de reconto de história infantil e de letramento propostos pela professora foram gravadas em áudio e vídeo para nossas análises na abordagem da metodologia qualitativa. Essa perspectiva nos propiciou estudar processos educativos considerando a psicologia do desenvolvimento da pessoa em sua singularidade, para tal, utilizamos o episódio como unidade de análise.

${ }^{1}$ A mediação da fala, do desenho e da escrita na construção de conhecimento da criança de seis anos. (Tese de Doutorado em Processo de Desenvolvimento Humano e Saúde). Universidade de Brasília, Brasília, 2010. 
Partimos do pressuposto que o processo de desenvolvimento cultural da criança se relaciona à aprendizagem do uso dos sistemas simbólicos como ferramentas culturais, entre eles, a linguagem, a escrita e as imagens. Esse processo avança à medida que a criança pequena participa de interações e vai compreendendo o uso e as funções dos mediadores instrumentais e simbólicos, atribuindo-lhes novas funções como meio de atingir seus objetivos.

Vivemos numa época em que novas perspectivas de alfabetização e letramento de crianças têm sido impulsionadas pelo desenvolvimento da tecnologia da comunicação on-line e têm ampliado a nossa forma de construir conhecimento gráfico, como os diferentes tipos de resolução ]em imagens, sons e escrita pelos quais informações são veiculadas em multimídias, em tempo real, de qualquer parte do planeta. É insuficiente conhecer a correspondência fonema/grafema: temos também que acompanhar a leitura das imagens e utilizar as maneiras características da comunicação com vários interlocutores simultaneamente.

Portanto, neste artigo, trataremos o processo do desenvolvimento cultural se construindo no ensinar e no aprender de uma pedagogia dialógica (ALEXANDER, 2003; 2005), isto é, a criança aprendendo com o outro em interações dialógicas, numa perspectiva de alfabetização ampliada, em que o aluno usa várias formas para poder aprender e aplicar a escrita, mediadas por falas egocêntricas para realizar seus desenhos e suas escritas livres que estaremos denominando aqui de produções gráficas livres. Essas atividades são construídas nas práticas sociais do letramento multimodal que se baseia nos vários modos de comunicação - oral, visual e gráfico (DYSON, 2008; KENDRICK; MCKAY, 2004).

\section{II - Pedagogia dialógica e o desenvolvimento cultural da criança de seis anos}

O desenvolvimento cultural da criança está relacionado com o uso 
dos sistemas simbólicos como ferramentas culturais e podem ser observados em situações experimentais de resolução de problema dado à criança, por exemplo, que envolva a função psicológica elementar de memória. A solução ultrapassa sua capacidade natural de resolvê-lo quando há inclusão de um signo na direção da solução, funcionando como uma ferramenta cultural de realização da operação psicológica subjacente ao problema. Uma criança pode pegar uma figura, fazer uma associação e conseguir lembrar do que era preciso; outra pode não entender essa relação ainda. O que difere uma criança de outra será a operacionalização da ferramenta mediadora para solucionar o problema (VIGOTSKI, 1994): a que fez o uso de símbolos auxiliares para lembrar, criou dispositivos internos em seu desenvolvimento cultural que ajudam a aumentar a função de memória (LURIA, 1992a, 1992b). Quanto mais elaborada for a ação de uso auxiliar de ferramentas culturais, maior complexidade dos dispositivos internalizados da criança, chegando a ponto de dispensar o uso de mediadores.

Nessa perspectiva, o desenvolvimento das ferramentas culturais enfatiza o papel da escola enquanto espaço que favorece novas possibilidades de intervenção do adulto ou criança mais experiente no ensinar e no aprender infantil, ao disponibilizar as situações e os recursos materiais na sistematização dos conteúdos necessários à mediação das ferramentas simbólicas na construção de conhecimentos de cada criança na experiência comum, coletiva, ou individual. Destaca-se, também, o papel do professor em ativar as zonas de desenvolvimento proximal (ZDPs) (VIGOTSKI, 1987) em situações de ensino-aprendizagem com a criança, ao negociar a solução de tarefas que envolvam a escrita, oferecendo suporte à criança (BRUNER, 1975) que aprende a dominar os usos e funções das ferramentas culturais mediadoras, canalizando a construção de conhecimento. As condições auxiliares envolvem o fornecimento de pistas relacionando desenho com escrita, narrativa, escuta da fala egocêntrica da criança, tradução de escritas livres em norma culta. 
A organização do ensino, que possibilita formas variadas de a criança de seis anos aprender, contribui para seu desenvolvimento cultural. Estudos contemporâneos sobre a aprendizagem têm valorizado a ação da criança sobre os objetos de conhecimento em sua atividade de aprender e lúdica (EL'KONIN, 1999; DAVYDOV, 1995) ${ }^{2}$. Neste sentido, enfatizamos que a efetiva construção de conhecimento do objeto cultural em sala de aula se apresenta em uma dinâmica entremeada por contradições em que descrição, correlação imagem-objeto ou qualquer atividade sobre o objeto é feita com/pelo aluno e não apenas pelo professor e/ou autor do livro escolar, de forma artificial e congelada no tempo (ILYENKOV, 1974).

Neste trabalho, consideramos a sistematização da escrita, não apenas entendida como ensino da técnica de codificar fonema/grafema, mas como início do processo de construção da compreensão e produção textual; isto é, como processo conceitual que requer entendimento de seus usos e fúnções, como objeto existente na sociedade e, portanto na escola (ILYENKOV, 1974).

Assim, a sistematização da escrita na escolaridade da criança de seiß anos considera a dinâmica do aprender e do brincar. Estando em atividade de aprender quando está descobrindo a regra da escrita alfabética,_também utiliza as funções do brincar para aprender (BARBATO, 2008). A participação do professor está em apresentar as práticas de letramento de várias maneiras: envolvendo diversão, relação imagens e letras no reconto de livros, conhecimento real de sons e letras e tarefas que contenham ação sobre a escrita - produção de elaborações gráficas livres, narrativas, registro de passeios, entre tantas outras. Enfatizamos, ainda, que esta forma de a criança aprender o objeto escolar cultural amplia a compreensão, a ação e a modificação ativa do objeto com a participação e a troca de experiências com o outro - em interação com as outras crianças e o professor - pelos

\footnotetext{
${ }^{2}$ Esses autores russos consideram que quando a criança é pequena a atividade lúdica prepondera sobre as demais e para a criança escolar é a atividade de aprender a mais importante.
} 
modos de comunicação no coletivo da sala de aula.

Portanto, nesse ambiente escolar, a atividade da criança em desenvolvimento cultural e as trocas dialógicas na construção do conhecimento requerem qualidade de diálogo, inclusive na escuta do aluno por parte do professor. A pedagogia dialógica considera a escola como uma micro-cultura na qual se dão as interações interpessoais mediadas pela fala, principalmente nas salas de aula - espaços onde ocorrem as atividades especificas de ensino, organização do trabalho docente, discente, do tempo, assunto, avaliação, rotinas, entre outras (ALEXANDER, 2003; 2005). Defendemos que o dialogismo ocorre nas relações professor-aluno quando ambos podem falar e ser ouvidos e não predomine o discurso pedagógicó de pergunta-resposta por parte do professor e, às vezes, sem muita atenção à fala da criança (PONTECORVO; AJELLO; ZUCCHERMAGLIO, 2005, BRUNER, 2001).

A escola é uma micro-cultura, enquanto uma organização que distribui funções, poderes e desempenha vários papéis para promover a educação da população da comunidade em que está situada. Ela recebe, em seu interior, crianças, professores, funcionários de variadas camadas sociais e falantes de variantes da língua com modos de vida peculiares. Os diálogos que se travam no ensino-aprendizagem estão imbricados nessa diversidade cultural, pois a cultura se constitui como resultado do embate nas interações interpessoais colaborativas, das negociações de significados, dos acordos e dos desacordos (MATUSOV et al., 2007; LEE, 2007).

\section{III - As práticas de letramento multimodal}

Em sociedades com tradição letrada, a escrita tem início com a inserção da criança nas práticas familiares e comunitárias (KLEIMAN, 1995). O processo de letramento de uma criança retrata as práticas sociais e as funções de escrita presentes na comunidade em que vive, de acordo com 
as situações concretas em que a escrita é utilizada. A criança experiencia as tomadas de decisão junto com o outro depois que este outro lê. Assim, quando vai para o contexto escolar aprender a ler e escrever, a criança vai relacionando o que conhece da escrita de suas experiências de casa com as da escola e vice-versa (BARBATO, 2007; SCHOLZE; RÖSING, 2007).

Atualmente, a democratização do acesso à informática e às multimídias no mundo globalizado tem provocado uma reviravolta nas formas de utilizarmos os diversos modos comunicativos - oral, escrito e visual. Os diferentes tipos de resolução em imagens, sons e escrita pelos quais as informações estão sendo veiculadas em tempo real têm ampliado "glocalmente"3 (CANCLINI, 2003) a nossa forma de construir conhecimento gráfico, mudando e expandindo, assim, nossa conceituação em alfabetização e letramento. Adotamos o termo "letramento multimodal" por abarcar a pluralidade de meios que dispomos para produzir e ler textos de gêneros multifuncionais, isto é, aqueles que combinam diferentes sistemas simbólicos (DESCARDECI, 2002; DYSON, 2008).

É importante que a escola, enquanto espaço em que se exerce a negociação de saberes consolidados com aqueles que estão em construção, em plena era digital, acompanhe os novos usos e funções dos modos oral, escrito e visual como mediadores da aprendizagem e da escrita de seus alunos.

\section{IV - A fala e o desenho na sistematização da escrita}

No momento atual de construção das interações dos modos comunicativos na produção de conhecimento na e sobre a escrita, torna-se mais importante desenvolvermos estudos sobre a construção do processo de simbolização de cada criança em sua singularidade enquanto participante de uma cultura, considerando-se as interpretações construídas sobre os usos e

${ }^{3}$ Glocal se refere às práticas culturais e suas interrelações nos espaços global e local. 
funções da fala e do desenho em relação à aprendizagem da escrita nas demandas interativas nos diversos contextos.

O desenho é uma das expressões da função simbólica que se concretiza na relação entre o indivíduo e a cultura, na sua história. As famílias e os professores disponibilizam papéis, lápis, giz de cera como meios culturais com os quais a criança pequena desenha. E, por estar inserida em interações com um mundo de imagens desde o seu nascimento, ao longo dos anos a criança supera as marcas iniciais, aquelas aleatórias sem intenção de representar (garatujas), para construí-las enquanto objetos semióticos.

Consideramos que necessariamente a criança não passa por etâpas universais para o desenvolvimento cultural do desenho e da escrita, tanto pelas condições socioculturais em que a criança vive como pelas variadas possibilidades de aprender e desenvolver criadas nas culturas. (ANNING; RING, 2009; FERREIRA, 2005; IAVELBERG, 2006; SILVA, 2002). Por meio dos desenhos é possível conhecer as características culturais do coletivo em que as crianças vivem (GOBBI, 2007; HAWKINS, 2002, MCKAY; KENDRINCK, 2001), assim como as idiossincrasias (os aspectos individuais), além de o desenho infantil, à sua maneira, transmitir alegria, tristeza, frustrações, confiança pela função de comunicaçẫo do desenho (KITAHARA; MATSUISHI, 2006; PILlOTTO, SILVA; MOGNOL, 2004).

Quanto à escrita, adotamos em nossos estudos a perspectiva sociocultural que aborda a linguagem escrita enquanto sistema simbólico e arbitrário. Inicialmente, foi definida por Vigotski (1998) que estabeleceu uma relação que se constrói desde o gesto, a ação de brincar, o desenho até a escrita formal com signos, numa perspectiva conceitual de alfabetização mais ampla, em que a escrita inicia-se no gesto e na brincadeira de faz de conta, mediando importantes construções de conhecimento da criança sobre o mundo que a cerca. $\mathrm{O}$ desenho tem o papel de favorecer inicialmente a 
mediação gráfica. Estudos do Vigotski (1998) apresentam o desenho como um dos primórdios da escrita. Ele notou que, quando a criança libera seus repertórios através do desenho, ela o faz à maneira da fala, contando uma história. Assim, para ele o desenho é uma linguagem gráfica que surge tendo a linguagem verbal como base. Desenvolve-se em relação dialética com a fala e com outras formas de mediação semiótica por significar graficamente os objetos referentes que, também, são representados por sons da fala.

Luria (1988) observou que o desenho da criança tornava-se linguagem concretizada, quando representava simbolicamente algumas frases mais ou menos complexas em seu estuddo experimental com crianças que ainda não sabiam escrever convencionalmente. A tarefa consistia em fazê-las relembrar de certo número de frases utilizadas pelo pesquisador e, como previsto em estudos de desenvolvimento psicológico, ele introduziu elementos que dificultavam a tarefa. Neste caso, o número de frases excedia a capacidade das crianças de recordar, a fim de levá-las criar novas ferramentas mediadoras para concluir a atividade com sucesso. Papel e lápis foram entregues a elas, para que pudessem utilizá-los como recurso de memória. Luria observou que, inicialmente, as crianças desenhavam traços significativos para elas e que, gradualmente, iam colocando figuras e desenhos ocupando espaços diferenciados do papel. As mais velhas já utilizavam signos próximos aos utilizados na escrita. As crianças conseguiam se lembrar das frases, porque davam sentido às anotações gráficas representadas.

O estudo de Luria indica que a construção infantil do conceito de escrita parece passar da linguagem pictográfica, com desenhos, para a ideográfica, na qual as relações e significados são representados por sinais simbólicos abstratos. Essa transição se concretiza quando a criança coloca a mediação da fala na criação de sinais escritos, representativos dos símbolos das palavras. Para tal, a criança faz a grande descoberta: pode desenhar não 
somente objetos, mas também a fala. Nesse sentido, o ensino da união da fala e da escrita é organizar e preparar adequadamente essa transição, essa descoberta, e aperfeiçoar o método para o desenvolvimento da escrita (VIGOTSKI, 1998). Chamamos essas descobertas de produções gráficas livres, aquelas que a criança produz ao simbolizar, por meio de expressões gráficas, as relações com objetos culturais internalizadas das experiências em novos processos interativos (VIGOTSKI, 1998), quase sempre acompanhadas da fala.

Além de a fala desempenhar um papel importante como um dos sistemas simbólicos de que a criança dispõe, as falas social, egocêntrica e comunicativa também servem de base para o desenvolvimento de outros sistemas simbólicos - a fala aparece nos desenhos como se contasse uma história e nas escritas iniciais, quando a criança escreve como fala. Outrossim, no âmbito intrapsicológico, a fala é reguladora da ação infantil, visto que a criança passa a organizar seus atos por meio dela. É o caso da fala egocêntrica, que não é apenas falar sobre o que se está fazendo, mas buscar a solução para uma situação vivida. Isso configura uma ação psicológica complexa (VIGOTSKI, 1987; 1998; LURIA, 1987).

Neste trabalho utilizamos a fala egocêntrica com_a função apresentada por Vigotski $(1987,1998)$ de auto-regulação da criança e de regulação das ações, reconhecendo ser Piaget (1993) quem propôs a denominação egocêntrica, quando observou que as crianças falavam mais para si, sem se preocupar com o outro. Entretanto, a função vigotskiana desse tipo de fala tem o caráter de organizar, de planejar a ação da criança. Além disso, em nossa pesquisa, a fala egocêntrica de uma criança pôde desencadear diálogo entre os colegas que estavam por perto dela, ao se interessarem pelo assunto veiculado nesse enunciado.

Estudos contemporâneos (BERK, 1994, 2006; BERK; SPUHL, 1995; MONTERO; DIAZ; HUERTAS, 2001; WINSLER; DIAZ; MONTERO, 1997; WINSLER; NAGLIERI, 2003) sugerem as funções 
vigotskianas da fala egocêntrica nas crianças que falam para si mesmas na realização de atividades cotidianas e escolares. Quando a criança encontra dificuldades na realização de tarefas, sua fala funciona como autoreguladora e assume, gradativamente, o controle do que antes era exercido com a ajuda do adulto no desenvolvimento e na execução de tarefas, trabalhando como ZDP. Outra função encontrada para a fala egocêntrica está relacionada com a melhora de aproveitamento da tarefa realizada pelas crianças pequenas que usaram livremente essas falas. Além dessas funções, os estudos confirmam que, na estratégia de fala das crianças pequenas, predomina a fala egocêntrica externalizada; depois, com o tempo, o predomínio passa a ser da fala parcialmente externalizada, podendo apresentar manifestações labiais ou sussurros; em seguida a preponderấncia da fala interna. Outro estudo mostrou que a quantidade proferida de fala egocêntrica pela criança aumenta quando ela está entre pares em situação experimental de desenho (RAMÍREZ, 1991).

Vigotski (1987) sugere que a fala egocêntrica possa entremear a fala interna, sendo assim as crianças mais velhas, no ensino fundamental, agiriam sobre as dificuldades de modo diferente das mais novas da educação infantil, predominando a resolução em silêncio. A internalização_da fala, que antes era a forma externalizada de pensar alto, demonstra a importância teórica e a necessidade de estudos em situações sócio-históricas diferenciadas em que as práticas culturais se diversificaram pela possibilidade de que novas atividades gerem novas formas de mediação instrumental e simbólica que por sua vez geram novos usos e funções da fala egocêntrica para o desenvolvimento do pensamento humano. As crianças de seis anos, por exemplo, por estarem no período de transitoriedade de criança pequena para a escolar, podem apresentar as três estratégias de fala acima apresentadas, com predomínio ora da fala egocêntrica, ora dos murmúrios e movimentos labiais ora em silêncio; portanto, do pensamento internalizado e mudanças da fala social em fala 
comunicativa.

Os estudos da fala egocêntrica em nossa pesquisa empírica também indicaram a fala organizando as produções gráficas livres em que a criança desenhou e escreveu expressando seu conhecimento de objetos e práticas culturais, suas intenções, suas escolhas e seus esforços intelectuais na realização das tarefas. A fala exerceu uma função importante nas produções gráficas livres contextualizadas no letramento multimodal. A íntima relação entre fala, aprendizagem e experiência social em contexto de alfabetização fez com que a criança falasse para si mesma em voz alta para organizar sua atividade gráfica, nomeasse o que ia fazer e contasse a história de seu desenho, ou soletrasse a relação fonema/grafema, por exemplo, quando tinha que colocar uma letra na sua escrita.

\section{V - O estudo empírico da fala egocêntrica nas produções}

\section{gráficas livres}

Com o objetivo de analisar os usos e as funções da fala egocêntrica nas produções gráficas livres - o desenho e as escritas iniciais - gravamos em áudio e vídeo quatro sessões no contexto da sala de aula de primeiro ano do ensino fundamental, focando em quatro crianças de seis anos: Clara, Daniel, Felipe e Renato em quatro tipos de atividades de letramento, sendo três de reconto de história infantil e uma de escrita livre proporcionadas pela professora da classe. As crianças do estudo são aquelas cujas mães foram entrevistadas como parte de um estudo mais amplo sobre práticas de letramento em casa.

A partir de nossas gravações dos diálogos nas mesas das crianças, recortamos as falas que elas proferiam para si mesmas e categorizamos em: Fala Egocêntrica Externalizada e Irrelevantes, Fala Egocêntrica Externalizada e Relevante e Manifestação Externalizada e Relevante, definidas por Monteiro, Diaz e Huertas (2001), e em Fala Egocêntrica 
Geradora de Fala Comunicativa, encontrada por nós.

Primeiramente, nossos resultados indicaram que a fala consolida a importância da pedagogia dialógica para o ensino da criança de seis anos pelo aprender e desenvolver nas trocas dialógicas com o outro, seja a professora ou outra criança. Conseguimos gravar os usos dessas falas egocêntricas, com a função de organizar seu desenho, anunciando o que ia desenhar, contando a narrativa da história ao desenhá-la. Enquanto que para a escrita, soletrando a relação fonema/grafema a fim de descobrir qual letra empregaria na palavra ou texto que estava escrevendo. Como já afirmamos, as falas egocêntricas estudadas em escolas aparecem com maior frequência quando as crianças estão enfrentando momentos de dificuldades. No\$sos resultados delineiam uma função específica da fala egocêntrica para a escrita, a de soletração. Quando a criança está tentando escrever ou copiar significativamente uma palavra, ela fala para si, não por estar em dificuldade, mas para entender o mecanismo subjacente na relaçãa fonema/grafema. Ela repete várias vezes o som, há um esforço intelectual em descobrir qual letra faz aquele som. A criança tenta relacionar ao som. os conhecimentos prévios como o próprio nome, outros nomes conhecidos ou similares e os ensinamentos da professora, do colega ou dos membros familiares_para essa descoberta, enfim às práticas sociais de letramento. A seguir um trecho do episódio de Felipe na primeira sessão gravada em que ele está desenhando numa mesa com mais dois colegas, uma menina e outro menino. Felipe vai anunciando sua história enquanto vai desenhando:

Felipe - Ela ganhou um neném, agora eu vou pro hospital e o neném.

Felipe - Um carro uuuuu... Tamo com pressa.

Felipe - Furou Pneu.

Felipe - Chegou no castelo.

Menino - Chegou no castelo? Deixa eu ver.

Felipe - Meu carro. Meu carro furou o pneu.

Felipe - Menino tacou uma pedra no carro. 
Menino - Quem?

Felipe - O menino tacou a pedra.

Felipe - Vou fazer primeiro a torre.

Felipe - $\mathrm{O}$ castelo.

Menino - O rei ali.

Felipe - Tô fazendo primeiro a torre está aqui.

Menino - Torre? Que torre?

Felipe - A torre que a princesa fica presa.

Menino - É isso?

Felipe - Isso aqui é a torre e o castelo que ela fica e o quarto.

Felipe - Olha aqui. Olha esse o quarto que ela ficou presa, em cima da torre, a torre é bem alta.

Felipe - O castelo da princesa Fiona, o nome dela é Fiona.

Felipe mostrava o desenho quando solicitado e fazia sua narrativa com falas egocêntricas e falas comunicativas. Em sua fala egocêntrica, Felipe usava os personagens de outra história conhecida, utilizando conhecimentos prévios advindos de suas experiências com livros de histórias infantis (BARBATO, 2008). A criança leva essas questổes ao texto, partindo de seu cotidiano, de sua diversão e de seu imaginário. Neste diálogo, os questionamentos das crianças levantaram oportunidades de relacionar conhecimentos novos com os já existentes.

Estudando as falas egocêntricas das crianças de nossa pesquisa, nossos dados indicam novas funções específicas para os usos da fala egocêntrica, ainda não relatadas na literatura. Ao analisar os usos das falas gravadas das crianças no processo de realização das produções gráficas livres foram evidenciadas as funções geradoras de construção de conhecimento na intersubjetividade. Como primeira função, encontramos o uso da fala egocêntrica geradora de comentários por parte da criança interlocutora. No exemplo acima citado, o menino ouvinte quer ver o castelo, a torre, o menino que tacou a pedra no pneu, até questionando a 
veracidade da fala.

O uso da fala egocêntrica com a segunda função: gerar na própria criança que proferiu a fala egocêntrica, um comentário para as demais crianças da mesa. Por exemplo, uma menina falou que ia desenhar o castelo e a princesa e depois convidou outras colegas a desenhar o castelo e a princesa. Reproduzimos abaixo o trecho do diálogo do episódio da Clara sentada à mesa com mais três meninas:

Clara - Eu vou fazer um castelo... Vamos fazer um castelo?

Risadas.

Clara - O cabelo dela.

Clara - Gente, aqui é a coroa e aqui é o cabelò dela, a bunda.

Meninas - É, é, é...

Clara - Aqui é o rei... Este daqui é rei, gente.

Menina - Do casamento, da coroa de mel.

Menina - Para! Clara.

Risadas

A fala egocêntrica encontrada foi o anúncio do que ia desenhar. "Eu vou fazer um castelo"; "O cabelo dela". E logo Clara socializa o desejo de desenhar com as colegas quando pergunta: "vamos fazer um castelo?"; “Aqui éo rei... Este daqui é rei, gente.” A partir dessas falas egocêntricas, ela se tornou seu interlocutor falante, ao propor para o coletivo aquilo que propunha para si mesma, e assim gerou o diálogo com as colegas.

O uso da fala egocêntrica com a terceira função: de gerar outras falas egocêntricas em outras crianças. Renato e mais três meninos na mesa nomeavam seus desenhos para o gravador, falando várias vezes os personagens e elementos da história, por exemplo, cama, príncipe, princesa, castelo, chuva. Consideramos esses enunciados como falas egocêntricas, pois eram anúncios dos próprios desenhos. O primeiro menino nomeou os elementos desenhados que apareciam na história para o gravador, logo os demais alunos da mesa também passaram igualmente a nomear seus 
desenhos. O vídeo mostrou os quatro meninos em pé, debruçados sobre o gravador, falando ao mesmo tempo os seguintes enunciados:

- Aqui tem o sapinho, a janela.

- A janela a florzinha, mané rapá.

- Florzinha? Mané rapá.

- Tá doido? Rapá.

- A florzinha.

- E aqui a chuva, árvore, cama dura, a minha calcinha aqui, hi.

- A árvore, a chuva, a princesa e o castelo, mané.

- Espera aí é a chuva, a princesa, os caçadores e o castelo.

- Princesa, caçadores, o meu nome, data, chuva.

- Meu nome e data e o castelo cama de predra.

- Não é de predra.

À medida que iam anunciando seus desenhos, refletiam e procuravam na atividade alguma palavra ainda não dita. $\mathrm{O}$ que gerou adição coletiva de conhecimento, pela ampliação de elementos da história. A mediação da fala nessa co-construção de conhecimento desencadeou a quarta função da fala egocêntrica encontrada em nossa pesquisa, a de avaliação, ao gerar questionamentos quando alguém dizia algo errônee, por exemplo, os desenhos que não apareciam na história, funcionando como ZDP por ampliar e avaliar o conhecimento que tinham de seus desenhos e dos desenhos dos outros. Portanto, os meninos avaliavam a si e aos colegas, gerando a passagem da fala egocêntrica para a fala comunicativa.

Encontramos ainda o uso da fala egocêntrica de soletração da relação fonema/grafema de uma criança com a função de gerar outras falas egocêntricas de soletração nos outros colegas da mesa, a que chamamos de fala egocêntrica coletivizada. A fala egocêntrica e de soletração da relação fonema/grafema do Daniel, gerou as soletrações de Felipe e Renato, como uma ZDP, a oportunidade de aprendizagem coletiva. Apresentamos esse diálogo a seguir: 
Daniel - SAPO SAPO é A.

Felipe -É sa sa po ó ó sapó, começa com S SAPO.

Daniel - Não é. Ah! É ó.

Felipe - SA A PO O.

Renato - Cadê o sapo.

Daniel - Aqui SA PÓ PÓ é Ó.

Renato - SA SA PO.

Felipe - S S A PO PO Ó.

Daniel - O P Ó.

Felipe apresentou a fala egocêntrica depois da fala de Daniel, "É SA SA A Ó Ó SAPO, começa com S, SAPO" apontando o cartaz da parede (cartazes com a palavra escrita, letra inicial e sua representação imagética) repetindo o nome da palavra que estava descobrindo, o nome da letra, soletrava relacionando fonema/ grafema, contribuindo assim para a fala egocêntrica coletivizada de soletração, com dêiticos para confirmar sua argumentação de como se escreve a palavra. A criança que não conhece as letras, ouve a resposta do colega e vai aprendendo. A atividade de aprender com o outro, pode consolidar o que já se sabe, mas principalmente gerar novas aprendizagens do que não se sabe, gerando ZDP, ou seja, as possibilidades de desenvolvimento que estão por vir (VIGOTSKI, 1998).

E, finalmente, o uso da fala egocêntrica da criança com a função de gerar no outro, professora, comentários de concordância ou discordância, no diálogo envolvendo os desenhos e a soletração da escrita livre. Nossos resultados se encaminham para a fala egocêntrica na perspectiva de Vigotski (1987, 1998) que tem a função reguladora e organizadora do pensamento/ linguagem na ação da criança, direcionada para o outro, como se de alguma forma, o que a criança estava dizendo pudesse obter concordância ou discordância do outro social. Evidenciamos esse processo no diálogo abaixo do Felipe quando foi contar para a professora a história que desenhou: 
Profa. - Ah! Que ótimo! Esse é o fio dental, é? Escreve o nome deles (desenhos), ó. Esse aqui?

Felipe - Menino.

Profa. - Então escreve para mim embaixo, escreve para mim embaixo.

Felipe - MÉ - NI - NO.

Profa. - MÉ - NI - NO.

Felipe - É?

Profa. - Isso.

Felipe - I?

Profa. - Isso.

Felipe - E o Ó?

Profa. - Isso. Agora aqui, esse aqui mesmo?

Felipe - Fio dental. Fio eu sei como é. É o "F”, né?

Profa. - Isso, põe lá.

Felipe - FIO (coloca um I).

Profa. - Isso. FIÓ.

Felipe - (coloca um O).

Profa. - Ó, isso. FIO DEN - TAL. D E N, D E N?

Felipe - DEN, qual a letra, mesmo?

Profa. - DEN, DEN.

Felipe - DEN, DEN, DEN, DEN, D!

Profa. - Isso, coloca aí. Aí. D E N; ó D E N.

Felipe - DEN, DEN.

Profa. - Olha, DEN, DEN.

Felipe - E?

Profa. - Isso. Agora aqui ó, T A LLL. FIO DENTAL, TAL.

Felipe - É o A.

Profa. - TAL, agora no final, olha aqui para mim. Qual é a última letra de T

\section{A L ?}

Felipe - É o U, é o U. 
Profa. - Então põe. Isso, muito bem, ótimo. Parabéns!

As falas egocêntricas do Felipe geraram sucessivas ZDPs pelas falas de apoio da professora ao complexo processo de soletração da relação fonema/grafema, seguindo a seguinte dinâmica: ele inicia pronunciando a palavra MENINO; a professora repete; ele pede a confirmação da letra que descobrira; a professora confirma e o incentiva ir adiante. Felipe continuamente pronunciava, descobria a letra e pedia confirmação, e a professora repetia e passava para a soletração seguinte e assim sucessivamente. Felipe usou a dinâmica da experimentação em que ele refletia sobre o som, procurando conhecimentos prévios e tentava descobrir qual letra o representaria, até chegar na descoberta da letra e, assim, pedia a confirmação da professora.

\section{VI - Considerações finais}

$\mathrm{Na}$ reunião das três ferramentas culturais, a fala egocêntrica se constitui como organizadora do desenho e da escrita. Ela permite que a criança anuncie o que vai desenhar e escrever e, assim, planeje sua predução gráfica livre, estabelecendo o conhecimento que tem sobre o assunto na forma de falar. E com as funções da fala egocêntrica geradora de fala comunicativiva, que-encontrames no nosso estudo, essa organização passa a ocorrer na troca dialógica entre pares e com a professora, com ampliação das possibilidades de aprender e de desenvolver a construção de conhecimento, compartilhando as informações trazidas das práticas de letramento multimodal da escola, da família e da comunidade, enquanto realizam as suas produções gráficas livres.

Essas relações estabelecidas entre a fala, o desenho e a escrita modificam a maneira de olharmos para o desenvolvimento cultural da criança de seis anos. O que se pensava ser apenas falatório sobre rabiscos, palavras e desenhos inventados, vimos ter vários usos, exercendo funções 
diferentes. Quando valorizamos e permitimos as produções gráficas livres da criança, estamos deixando que ela utilize a fala e suas produções de desenhos e escritas como dispositivos culturais para o processo de construção de novos conhecimentos e como avaliação dos que já possui, na escolarização do primeiro ano do ensino fundamental.

\section{Referências Bibliográficas}

ALEXANDER, R.. Pédagogie, Culture et Comparison: visions et versions d'école élémentaire. La Revue Française de Pedagogie. 142, 5-19, 2003. Disponível em de <http://www.persee.fr/web/revues/home/ prescript/article/rfp_0556-7807_2003_num_142_1_2927>. Acesso em: 14 out. 2008.

ALEXANDER, R.. Culture, dialogue and learning: notes on an emerging pedagogy. 10a. Conference of the International Association for Cognitive Education and Psychology (IACEP), Durham, 2005. Disponível () (2) (1) em: $<$ http://einstein.pslc.cs.cmu.edu/research/wiki/images/c/cf/Robinalexander_I ACEP_2005.pdf>. Acesso em: 14 out. 2008.

ANNING, A.; RING, K.. Os significados dos desenhos de crianças. São Paulo: Artmed, 2009.

BARBATO, S. B.. Letramento: Conhecimento, imaginação e-leitura de mundo nas salas de inclusão de crianças de seis anos no ensino fundamentăl. In:-Lia CHOLZE; Tania M. K. RÖSING (Orgs.). Teorias e práticas de letramento. Brasília: Inep, p. 273-287, 2007.

Integração de crianças de 6 anos ao Ensino Fundamental de nove anos. São Paulo: Parábola, 2008.

BERK, L. E.. Why children talk to themselves. Scientific American, p. 78-83, Nov., 1994.

BERK, L. E.; SPUHL, S. T.. Maternal Interaction, Private Speech, and Task Performance in Preschool Children. Early Childhood Research Quarterly, v.10, p.145-169, 1995.

BRUNER, J.. From communication to language: a Psychological perspective. Cognition 3, p. 255-287, 1975. 
BRUNER, J.. A cultura da educação. Porto Alegre, Artmed, 2001.

CANCLINI, N. G. Cultura híbrida. São Paulo: Edusp, 2003.

CAVATON, M. F. F.. A mediação da fala, do desenho e da escrita na construção de conhecimento da criança de seis anos. 2010. $204 \mathrm{f}$. Tese (Doutorado) - Instituto de Psicologia da Universidade de Brasília: Brasília.

DAVYDOV, V. V.. The Structure of learning activity. Journal of Russian and East European Psychology, v. 33, n. 4, p. 55-70, Jul./Aug., 1995.

DESCARDECI, M. A. A. de S.. Ler o mundo: um olhar da semiótica social. Educação Temática Digital. Campinas, v. 3, n. 02, p. 19-26. Jun., 2002.

DYSON, A. H.. Staying in the (Curricular) lines: practice constraints and Possibilities in childhood writing. Written Communication. v. 25, n. 1, p. 119-159, jan., 2008.

EL'KONIN, D. B.. On the Structure of learning activity. Journal of Russian and East European Psychology, v. 37, n. 6, p. 84-92, Nov./Dec., 1999.

FERREIRA, S.. Imaginação e linguagem no desenho da criança. Campinas: Papirus. 2005.

GOBBI, M. A.. O fascínio indiscreto: crianças pequeninas e a_criação de desenhos. In: FARIA, A. L. G.; MELLO, S. A.. (Orgs.). Territórios da infância: linguagens, tempos e relações para uma pedágogia para as crianças pequenas. Araraquara: J. M. Ed., p. 119-136, 2007.

HAWKINS, B.. Children's drawing, self-expression, identity and the imagination. Jade, v. 2, n.3, p. 209-219, 2002.

ILYENKOV, E. V.. Activity and knowledge, 1974. Disponível em Marxists Internet Archive: <http://www.marxists.org/archive /ilyenkov/works/activity/index.htm>. Acesso em: 14 out. 2008.

IAVELBERG, R.. O desenho cultivado da criança: práticas e formação do professor. Porto Alegre: Zouk, 2006.

KITAHARA, R. ; MATSUISHI, T.. Recherche sur les dessins des enfants. Journal of Disability and Medico-pedagogy, n. 14, p.15-19, 2006. 
LEE, C. D.. Culture, literacy and learning. New York: Teachers College Press, 2007.

KENDRICK, M.; MCKAY, R.. Drawings as an alternative way of understanding young children's constructions of literacy. Journal of Early childhood literacy, v. 4 n.1, p. 109-128, 2004.

KLEIMAN, A. B.. O que é letramento? In: (Org.) Os significados do letramento. Campinas: Mercado das Letras, p. 15-61, 1995.

LEE, C. D.. Culture, literacy and learning. New York: Teachers College Press, 2007.

LURIA, A. R... Pensamento e linguagem: as últimas conferências de Luria. Porto Alegre: Artmed, 1987.

O desenvolvimento da escrita na criança. In: VIGOTSKI, L. S.; ; LEONTIEV, A. N.. Linguagem, desenvolvimento e aprendizagem. São Paulo: Ícone Ed. USP, 1988.

The Child and his Behavior (Phases of the Cultural Development of the Child). In:

The child and his behavior (steps toward culture). In:

VIGOTSKI, L. S.. Ape, primitive man, and child: essays in the history of behavior, 1992b. Disponível em <http://marxists.org> Acesso em: 14 out. 2008.

MATUSOV, E. et al. Culture has no internal territory: culture as dialogue. In: VALSFNER, J.; ROSA, A. (Orgs.). Handbook of Socio-Cultural Psychology. New York: Cambridge University Press, 2007, p. 460-483.

MCKAY, R.; KENDRINCK, M.. Children draw their images of reading and writing. Language Arts, v.78, n.6, p. 529-533, jul., 2001.

MONTERO, I.; DIAZ, M. J.; HUERTAS, J. A.. El desarrollo de la motivación en el contexto escolar: un estudio a través del habla privada. Estudios de Psicología, v. 22, n. 3, p. 305-318, 2001.

PIAGET, J.. A linguagem e o pensamento da criança. São Paulo: Martins Fontes, 1993.

PILlOTTO, S. S. Duarte; SILVA M. K.; MOGNOL L. T.. Grafismo infantil: linguagem do desenho. Linhas, v. 5, n. 2, 2004. Disponível em 
<http://www.periódicos.udesc.br/index.

php/linhas/article/viewFile/1219/1033>. Acesso em: 14 out. 2008.

PONTECORVO, C.; AJELLO A. M.; ZUCCHERMAGLIO, C.. Discutindo se aprende: interação social, conhecimento e escola. Porto Alegre: Artmed, 2005.

RAMÍREZ, J. D.. Nuevas perspectivas metodológicas para el estudio del habla egocéntrica. Infancia y aprendizaje, n. 53, p. 119-134, 1991.

SCHOLZE, L. ; RÖSING, T. M. K. (Orgs.). Teorias e práticas de letramento. Brasília: Inep, 2007.

SILVA, S. M.. C.. A constituição social do desenho da criança. Campinas: Mercados das Letras, 2002.

VIGOTSKI, L. S.. Pensamento e linguagem. São Paulo: Martins Fontes, 1997.

- The problem of the cultural development of the child. In: VAN DER DEER, R.; VALSINER, J.. (Orgs.), The Vigotski reader. Oxford, UK: Basil Blackwell Ltd, 1994. Disponível em <http://www.marxists.org/archive/vygotsky> Acesso em: 14 out. 2008.

A formação social da mente. São Paulo: Martins Fontes, 1998.

WINSLER, A.; DIAZ, R. M.; MONTERO, I.. The role of private speech in transition from collaborative to independent task performance in young children. Early Childhood Research Quarterly, n. 12, 59-79, 1997.

WINSLER, A.; NAGLIERI, J.. Overt and Covert Verbal Problem-Solving Strategies: Developmental Trends in Use, Awareness, and Relations With Task Performance in Children Aged 5 to 17. Child Development, v. 74, n. 3, p. 659-678, may/jun., 2003. 


\section{Autoras}

Maria Fernanda Farah Cavaton

Faculdade de Educação da Universidade de Brasília

Contato: fernandacavaton@uol.com.br

Silviane Barbato

Instituto de Psicologia da Universidade de Brasília

Contato: barbato.silviane@gmail.com

Texto recebido em março de 2011.

Texto aprovado para publicação em junho de'2011.

\section{Como citar este texto:}

CAVATON, M. F. F.; BARBATO, S.. A fala egocêntrica da criança de seis anos na construção coletiva da escrita. Revista Acolhendo a Alfabetização nos Países de Língua Portuguesa,volume 1, nº 11, pp. 78 - 102, Set. 2011. Disponível em: 〈http://www.acoalfaplp.net>. 